\title{
POR UMA POÉTICA DA ATUAÇÃO REALISTA “ESTRANHADA"
}

Resumo

Interroga-se a atuação realista, analisando as suas premissas, investigando os seus limites, impasses e mecanismos de produção. Também decupa-se os seus registros constituintes, expondo procedimentos investigados em experiências práticas laboratoriais no cinema e no teatro, sistematizando e formalizando novos conceitos.

Palavras-chave:

Atuação Realista. Poética Cênica. Pedagogia do Ator. 


\section{POR UMA POÉTICA DA ATUAÇÃO REALISTA “ESTRANHADA"}

Rejane Kasting Arruda (UVV)

Rejane Kasting Arruda Professora Doutora da Universidade de Vila Velha. rejane7karruda@yahoo. com.br
No que diz respeito à produção atoral, o estranhamento foi conquistado, durante as Vanguardas do Século XX, com recursos como: o gesto-justo craiguiano, a estilização e o distanciamento brechtiano, a abstração do movimento em Barba, a mecanização em Meyerhold (recurso que no cinema está em Bresson). No entanto, a atuação naturalista ou realista também pode estranhar. A figura do vazio, por exemplo, pode ser fácil de identificação na atuação realista, com a exacerbação e o esgarçamento da cotidianidade. O cotidiano mata a progressão dramática, é algo esvaziado de sentido. Nos filmes de Lucrécia Martel, por exemplo, o tempo é dilatado de maneira a situar o vazio de pessoas que estão juntas sem qualquer motivação ou movimento em direção a algo. Mas não se trata apenas do sentido de um contexto ficcional. É uma questão formal. Por não haver a estrutura dramática, o tempo para. Existe um esvaziamento do sentido do tempo. A representação dramática se dilui a ponto de acharmos que estamos vendo um documentário: a câmera se escondeu e flagrou os passos improvisados das pessoas que ali vivem. Mas é ficção, em um dispositivo que se presta a desafiar a crença no que se está vendo: "será verdade?" - como diz Roubine (2003), "de tão real, alucina".

A psicanálise traz uma noção de poética como trabalho 
de uma borda entre o real e o sentido. O conceito de "real" de que se trata não é relativo à realidade, mas ao indizível, limite da linguagem; uma borda entre o que é possível ou não dizer - e, com a linguagem, fornecer existência.

Teorizar o real e a poesia implica lidar com a angústia da folha em branco tão transbordante de presenças e de desejo para, no depois, constatar certa ordem de ausências que se corporificou com as palavras, com o que não pôde ser dito nem estar ali e com o que restou fora no de-dentro elaborado. Esse jogo tenso e pendulante entre dizer e apagar no dito, entre presença e falta, entre tentativa de preenchimento e vazio, aponta um trabalho nas fronteiras e bordas (ABRAHÃO SOUSA, 2017, pp. 1-2).

Consideramos que é para esta impossibilidade de dizer - e fazer existir - que a arte aponta ao estranhar, trabalhando a área entre os enquadramentos em jogo e bordando-a. Ao articular esta ideia - seguindo em analogia -, podemos dizer que os cortes que compõem o jogo de enquadramentos cênicos, com seus vãos e vazios, flagram um espaço "de real", indizível, para o qual este jogo aponta (e seria este apontar o tal "efeito poético"). Por isso a questão de partir de fragmentos e juntá-los, criar os pedaços e juntá-los, criar as camadas e trocar coisas de lugar: para que, na composição final, se desenhe uma borda em que o real apareça enquanto perspectiva.

Não nos são distantes as ideias de anamorfose, informe, deformação, excesso, vazio, desafio aos limites da forma, dessubjetivação e descrença no olhar, utilizadas pelos psicanalistas lacanianos quando articulam a arte à figuração de um objeto a, que compreendemos como sem imagem, sem inscrição na linguagem, que não se pega, não se nomeia, não se vê. Pode-se dizer, ainda, como um "não lugar"; borda que se descola, para onde a arte é capaz de apontar. Lançamos as bases para um laboratório: para ser poética, é preciso figurar o objeto a. Sendo assim, nos deparamos com a perspectiva de, também, os atores apontarem para este limite da linguagem, ao manejarem os arranjos compostos por registros e materiais, de forma a provocar o estranhamento.
A escansão do tempo e a cotidianidade, quando levadas a certo limite, estranham - e investimos no fato de o naturalismo estranhar com a figura do vazio -, mas o manejo das escanções do tempo é uma modalidade apenas. $\mathrm{O}$ ator pode imprimir a visualidade do pensamento, utilizando-se da divisão de foco (SPOLIN, 2015) com uma atividade cotidiana que o distrai, enquanto foca na fala interna, isto é, o verbo oculto em escuta. O movimento das reverberações da fala interna faz dos olhos do ator uma espécie de janela; a borda de um espaço abstrato em que onde se situa o pensamento; "dentro enigmático", que o espectador não vê direito, tematizando o seu olhar. As bordas dos olhos do ator permitem um investimento do olhar do espectador em um espaço outro, fissura na espacialidade da cena. Percebe-se a visualidade do pensamento apontando para o limite do que se pode olhar.

Este registro da atuação naturalista pode ser invadido pela imobilidade. Neste caso, trazemos outro estranhamento, desafiando os limites da cotidianidade. A imobilidade gera um efeito de inumano: o homem-máquina, o morto-vivo, o fantasma. Esta figura também é um recurso com o qual se joga para desafiar as formas da atuação realista, abrindo a perspectiva de um hibridismo, com a experimentação das diferentes gradações entre um registro e outro. $\mathrm{O}$ excesso também é uma figura utilizada, seja de movimento ou afeto. No cinema - e estamos pensando aqui em recursos do Cinema Contemporâneo -, conforme a estética do filme em questão, ao se movimentar, o ator desafia a câmera a se ajustar para enquadrá-lo. Por segundos, o desenho do quadro se perde, a imagem borra, gerando um efeito de caos para, em seguida, voltar a se estabilizar, provocando saltos no olhar do espectador, que se restitua a partir do novo enquadramento. Este jogo depende do excesso de movimentos do ator; depende do ator.

A palavra registro denota algo que (registrado) retorna no corpo. Sem querer ou intencionalmente, a atuação implica algo impregnado na memória, em um espaço corporal de atualização de experiências e realização de formas que surgem como auxiliares no jogo. Estas formas ocupam o espaço corporal, preenchem o 
tecido dentro das bordas, muitas vezes se opondo ao enquadramento fílmico. Estes registros funcionam como matrizes (BURNIER, 2001) que, se o ator treinar, retornam. $\mathrm{O}$ ator brinca com estes registros. São eles que constroem a poética. É possível alternar a imobilidade com o excesso. Forma-se um vocabulário, que serve para desafiar os limites da forma da atuação realista. Existem limites para a utilização de cada registro, sendo tênues e, por vezes, declaradamente rompidos. Quando se volta a uma espécie de naturalismo primário, digamos assim, cuja presença da câmera é disfarçada, trata-se de conquistar o assombro causado pelo vertiginoso "efeito de realidade". A cena "torna-se um espaço de alucinação. $\mathrm{O}$ espectador acredita que está deixando o real na porta do teatro. $\mathrm{O}$ real o alcança no cerne do espetáculo e o lança na deliciosa confusão de uma percepção sem referências estáveis" (ROUBINE, 2003, p. 115).

Encontramos, em Bogart (2011), a produção verbal não enunciada do ator (fala interna, subtexto, subpartitura) tomada como um desvio (do foco) - não em função de uma representação, mas simplesmente para que, ocupando o foco de atenção, "o resto" (o caminho da criação) aconteça. Diz Bogart que Stanislavski "descobriu métodos para ocupar o lobo frontal do cérebro" e "deve ter compreendido que para entrar no paraíso é preciso ir pela porta dos fundos" (BOGART, 2011, p.129).

Stanislavsky inventou mecanismos úteis de distração (a porta dos fundos) para que você tire a si próprio do caminho a fim de obter espontaneidade e naturalidade (paraíso) no palco. A esses desvios úteis ele atribuiu nomes como "determinadas circunstâncias", "motivação", "justificação", "o mágico se”, "objetivos e superobjetivos" etc.

É digno de nota: a responsável pela disseminação do método do Viewpoints trata os procedimentos de verbalização stanislavskianos como "fabricação de desvios" e não "construção psicológica” (ou "psicologismo"), como são usual (e pejorativamente) tratados no Teatro Contemporâneo. De certa forma, ela autoriza procedimentos que implicam um enquadramento através da diegese (do personagem), mas, antes de tudo, são elementos em jogo que criam desvios (e não“psicologismo").

Seria preciso estudar os efeitos de cada modalidade proposta por Stanislavski, revisando os termos à luz do pensamento contemporâneo. O "mágico se", por exemplo, implica uma elaboração verbal que constrói uma fantasia possível sobre si, a perspectiva do sujeito-ator viver a situação ficcional em questão. Assim, o ator produz condições para um "eu circunstanciado" (em vez de dedicar-se ao ato de representação, imprimindo fatalmente os seus indícios e matando o realismo). Com a construção de um "mágico se", no lugar de representar, o ator se deixa levar por certa lógica, que se desenvolve imaginariamente, até chegar à situação da personagem. Com o princípio do desvio do foco, Bogart testemunha, também, uma articulação dos procedimentos de verbalização stanislavskianos com Spolin.

Ele se concentra em negociar o artifício - o tamanho do palco, a marcação, o texto, os figurinos, as luzes - até o ponto em que a mente consciente - que está de tocaia para nos tornar pequenos - fica ocupada com alguma outra coisa de modo que a espontaneidade e a naturalidade podem chegar sem ser impedidas (Idem, p. 130).

Constata-se, igualmente, a presença de um "elemento desestabilizador": "Não se pode criar em estado de equilíbrio. $\mathrm{O}$ desequilíbrio produz uma dificuldade que é sempre interessante no palco" (Idem, p. 131). O elemento desestabilizador pode vir de si mesmo, quando, sem querer, o ator faz algo inesperado, que contradiz todo o combinado; quando erra. Segundo Bogart, é preciso criar com isto: os erros e acidentes são produtivos; eles são "achados".

Normalmente, quando algo dá errado, nós recuamos. Queremos reavaliar. Será que esse impulso pode ser invertido? Será que podemos aceitar de bom grado a energia de um acontecimento inesperado? No momento em que as coisas começam a dar errado, será que podemos penetrar no evento em vez de nos esquivarmos dele? (Idem, p. 132)

A autora propõe uma articulação com 
Freud.

As coisas sempre saem erradas. É com um acontecer o que você não planejou. Sigmund Freud sugeriu que não existe acidente. Será que o acidente pode ser um sinal? Será que ele está chamando a nossa atenção? O acidente contém energia -- a energia de formas não controladas (Idem, p 132).

O contexto de jogo se impõe com novos elementos, avassaladores, perturbadores do arranjo anterior. Neste momento, o que estava estruturado passa a resíduo; as suas marcas são como húmus, memória, eco, passado. $\mathrm{O}$ que impera, no foco e no jogo de enquadre, passa a ser outra coisa. Assim, o jogo entre construir e destruir precisa ser posto em questão. $\mathrm{O}$ ator muitas vezes tem a ilusão de que o processo de criação se dará em linha reta, em uma única direção e à medida que vai colocando "tijolinho por tijolinho" - por assim dizer - no arranjo. No entanto, a obra se constrói com os cacos, desvios, subversões e pulsões, e destruições; força esta que talvez possamos relacionar com o que Artaud chamou de "vida" e que estamos procurando fundamentar na presença de elementos perturbadores e resíduos. O arranjo anterior torna-se o elemento perturbador da proposição atual "façam outra coisa"; registrado na memória corporal, aparece através de seu eco, reconfigurado, reabsorvido.

Evidências da Atuação Naturalista no Cinema: A Questão do Impulso para a Fala e a Produção Intencional de Imagens Internas

Desde 2011 ministro aulas de Atuação para Cinema e pesquiso procedimentos para os atores. A resistência aos procedimentos ou as dificuldades dos atores, a descrença ou preguiça para realizar um trabalho sistemático, muitas vezes conduziram à invenção de procedimentos intermediários. A fala interna é algo que causa estranheza, assim como a Memorização Através da Escrita ${ }^{1}$. O suporte no erro e no esquecimento, o jogo com a divisão de foco, o improviso com a sensação do vazio quando estamos em nome próprio em cena, soam estranhos para o ator que quer interpretar personagens.

No entanto, se representarmos um personagem, imprimiremos a visualidade desta representação em cena. Esta é a questão de partida, que diz respeito a uma demanda do Cinema Contemporâneo pela naturalidade, ilusão e efeito de realidade: não representar é o primeiro ponto. Assim, futuramente, $\mathrm{o}$ ator se deixará levar por um arranjo mais complexo do que apenas um dos elementos isolados, como o imaginário formado a respeito do personagem, que extraiu da leitura de um roteiro ou da fala de um diretor.

Exige-se, dos atores, a espontaneidade ou naturalidade; algo que imprima que as ações, falas, decisões, estão sendo realizadas no instante-já e não partiturizadas. O "efeito de impulso" é provocado pela troca - jogo que o ator maneja - entre os materiais. É no instante em que algo se intromete, diferente do que anteriormente ali estava, ocupando a sua escuta, que tal efeito acontece. Seja fora ou dentro, instantâneo ou planejado, é esta outra coisa se intromete a responsável pelo impulso. Mesmo no interior de uma partitura organizada, é no instante da troca entre as ações físicas, que a sua inscrição gera o "efeito de impulso". De maneira que a ação física não é consequência do impulso, mas sim causa. A perspectiva do ator registrar, na memória da tessitura corporal, uma forma que passa a ser instalada não mais pela reprodução intencional, mas pela memória - que a atualiza independente da intencionalidade -, denota a organicidade desta partitura física.

É da mesma forma que manejamos a troca entre fala interna e externa: para causar o efeito de impulso na fala. Se desviarmos o foco de atenção para uma frase que não será dita bem no instante anterior em que aquela que a substituir deve aparecer (externa), esta se inscreverá como impulso em substituição à primeira; assim, produz-se um desvio. $\mathrm{O}$ impulso é um mecanismo de troca. A fala externa é construída como impulso, porque o foco - o olhar e a escuta - sofreu um desvio e a esta retornou. Mas este mecanismo exige certo esforço - e é este investimento de energia que implica

\footnotetext{
${ }^{1}$ Procedimento de escrever o texto até memorizar para não se antecipar uma imagem vocal antes de ir para a cena.
} 
a fala no cinema (ou na atuação realista) como extra-cotidiana (Barba, 1994) mesmo que tenha a forma cotidiana.

Não é apenas o impulso que torna a fala realista. Esta precisa estar impregnada de cotidianidade. Trata-se de uma resolução formal específica: "quebrada", com repetições de fonemas, "encumpridamentos" de vogais, acelerações, ritmo inconstante, irregular. A fala cotidiana é irregular. Romper com a regularidade rítmica passa a ser regra de jogo para produzir o efeito de uma fala cotidiana (e de atuação realista). Tudo é jogo e toda proposição proferida em nome próprio para a construção desta estética é uma instrução de jogo. A presença de um registro pode ser uma instrução de jogo em foco. O que se denuncia é a complexidade deste jogo, com várias divisões de foco. Mas, aos poucos, não se pensa mais em seus elementos constituintes e o registro passa a ser natural, porque foi atualizado através da memória corporal e não mais através da intencionalidade.

A visualização kusnetiana pode ser relida a partir do conceito de "mente dilatada" de Barba (1995). O ator deve provocar um jogo com as imagens internas, desenvolvendo-as em saltos, como se fossem peripécias. No entanto, a proposição barbiana (coincidente com a de Meyerhold, frequentemente repetida), de que há uma ligação entre "mente e corpo" e que um corpo dilatado implica uma mente dilatada, pode levar à compreensão de que basta realizar a ação física para dilatar "a mente" (ou a imaginação). Contudo, na atuação realista é preciso provocar a imagem; produzir o enquadramento interno. $\mathrm{O}$ enquadramento interno situa o ator em relação a um material de estímulo oculto, cuja presença o permite improvisar com o externo (mesmo tendo uma partitura).

A estrutura deste trabalho, portanto, se sustenta em três lugares: o que o ator produz internamente (são pensamentos, falas internas e visualizações); o que ele "escreve" na cena, com o corpo e a voz (a materialidade da presença é letra, conjunto de traços, registros que vão implicar uma escuta múltipla); e o que o espectador escuta e vê (ou o que associa, ou como enquadra a produção cênica). Estes três lugares não coincidem. Por isso, a ideia de expressão "de dentro para fora" é equivocada. O tal "dentro" (o que só o ator vê e escuta) e o tal "fora" (que está aparente ao espectador e faz parte da escrita cênica) são lugares diferentes da estrutura que se sustentam com certa autonomia. Nesse caso, ocorre que os atores acabam por designar, como "dentro", a atualização dos registros (com a sua grafia de afetos e ecos, no interior da tessitura da memória corporal). Ao trazer de volta uma grafia de afetos, o corpo atualiza as suas marcas. Assim, estas formas "aparecem" sem que o ator pense em atualizá-las ou desenhá-las - parecendo mesmo vir "de dentro".

Existe certo deixar-se levar por estas atualizações, que, muitas vezes, são associadas ao impulso de dentro para fora. Mas, mesmo trazendo de volta um registro (e certa forma) através da tessitura corporal, o enquadramento plástico-corporal "fora" pode veicular outra. $\mathrm{Ou}$ seja, existe um dentro do corpo pulsante, mas não necessariamente esta grafia vai determinar o "fora", que depende da resultante do jogo com outros vetores. $\mathrm{O}$ que o corpo atualiza neste suposto "dentro" é apenas um dos materiais, heterogêneo em relação a outros, que estão presentes em um jogo de tensões. O desenho externo é moldado através de um jogo de absorções entre os enquadramentos. Conforme a música, a relação com o outro, o pensamento, os limites espaciais, temporais e etc., a resultante será uma ou outra. Dizer que se trata de um impulso "de dentro para fora" é ignorar os outros "dentros" e os outros "foras" em jogo. Existe um jogo entre as reverberações de todos estes materiais e suas incidências, e uma resultante formal sempre nova. Ao ler (escutar) o que o corpo atualiza, pode-se tanto associar algo novo, quanto manter o pensamento anterior, que se desdobra ao permanecer. Existem camadas de pensamentos. Pode-se pensar coisas diferentes ao mesmo tempo. Por isso, a noção de "empilhamento" é bem-vinda.

Um enquadramento cênico pode evocar, para o espectador, certo pensamento, mas os materiais que o ator guarda ocultos são outros. Existe um "desentendimento estrutural" (ou "diferença estrutural") entre o enquadramento interno atoral e o enquadramento produzido pelo espectador - a sua escuta e olhar. 
Isto dá liberdade para o ator produzir visualizações e escutas "alucinadas", "desconectadas" ou ao bel prazer. Pode-se manter a linha "do pensamento do personagem" enquanto material residual (com seu eco e sua incidência já trabalhada) enquanto se constrói novo pensamento em nome próprio, como reação ao jogo e ao outro. As combinações são múltiplas. Barba (1995) produz a definição de "mente dilatada" através de uma analogia com as transformações de uma história popular. A fábula se transforma cada vez que é contada. Da mesma maneira, o ator desdobra, completa a imagem interna a cada vez que precisa utilizá-la.

Paralelo ao trabalho interno de sustentação de imagens e da produção de trocas com falas internas para se imprimir a espontaneidade na fala, a poética do corpo se estabelece com certa autonomia. A partir dos estudos da performatividade de Austin, com a sua proposição de que "falar é fazer", pode-se dizer que, quando o ator está em cena, existem, no mínimo, duas linhas-de-ação: a da fala e a do corpo. Se "falar é fazer", existe a linha-de-ação da fala; e se, em cena, podemos imprimir ações físicas que independem da fala, existe a linha-de-ação inscrita através das formas do corpo. Enquanto espectadores, escutamos duas linhas: uma linha veiculada ao corpo e outra à fala. Trata-se de jogos de enquadramento; da visualidade de ações, que trazem um contexto a elas articulado, ou seja, organizações em espaços-tempo (ficcionais ou não).

A premissa da prática laboratorial do ator com a enunciação de uma fala é o jogo de múltiplas escutas destas duas linhas e de suas relações. Ou seja, o fato de existir a linha do corpo e a linha da palavra indica que há fissuras, diferenças e, também, o devir das relações entre elas. Há uma perspectiva de se confundir, de se atrapalhar na escuta; de cair no caos ou de não conseguir escutar; e de se escutar coisas opostas ao mesmo tempo; de se recortar sentidos contraditórios. Ou seja, a relação entre as linhas implica um devir do sentido na construção da poética, já que esta é fruto de uma relação entre caos e ordem, escuridão e recorte, ruído e som. Assim, desvinculamos a ação física da mimese do texto tal como normalmente é vista na cultura dramática. Uma das acusações ao trabalho com o texto é que a cena implicaria a mimese ou representação da diegese fechada capturada na sua leitura. Mas a proposição de duas linhas de ação cujas relações implicam sentidos móveis, traz a perspectiva de - mesmo quando agimos com a fala advinda de um texto dramático -, desarticularmos o trabalho corporal da sua representação, conferindo-lhe autonomia. Isto significa dar luz a um jogo de encaixes de visualidades diferentes que se tencionam. O trabalho com o texto dramático é sustentado pelo jogo de enquadramentos, tal como o trabalho com o pós-dramático. Se as fronteiras entre estes são borradas em função da unidade imaginária - da diegese, onde o ator está veiculado à ideia de personagem -, isto quer dizer que não há uma diferença estrutural, mas uma distinção de modalidade de jogo, cujas regras são outras. Enquanto no pós-dramático a regra é abrir a fissura que diferencia as camadas, no dramático é aproximá-las para disfarçar o corte que estabelece as diferenças.

\section{Como Dilatar em Cena: Caminhos Possíveis em "Quem Tem Medo de Plínio Marcos?"}

A produção da poética do corpo na atuação realista no Teatro se encontra com um problema: é preciso dilatar (BARBA, 1995). Quanto maior o espaço - uma questão de tamanho e de acústica -, mais se exige, do ator, dilatar. Mas a dilatação, enquanto instrução de jogo, não é suficiente. Não adianta colocar no jogo: “Dilata!”.

Quando apresentamos "Quem Tem Medo de Plínio Marcos?”2, no Teatro Carlos Gomes, em Vitória, em 2016, os atores não estavam acostumados com um espaço grande, mas apenas com salas multiuso e pequenos anfiteatros. Dedicamo-nos a uma posterior análise dos momentos em que um mínimo de dilação aconteceu - o suficiente para aquele espaço - e percebemos que o que a sustentou foi, princi-

\footnotetext{
${ }^{2}$ O espetáculo é formado por fragmentos da dramaturgia de Plínio Marcos: “Querô", "Barrela”, "Mancha Roxa”, "Abajur Lilás”, "Quando as Máquinas Param”.
} 
palmente, a tipificação e a "ação sobre o outro".

"Ação sobre o outro" é um conceito que criamos a partir de proposições de Javier Daul$\mathrm{te}^{3}$, formalizando, também, um treinamento com o mesmo nome. A ênfase está no enquadramento pela relação entre os atores, independente do enquadramento plástico-corporal, isto é, forma do corpo. Contrapomos estes dois tipos de enquadramento: o desenho - ou movimento - do corpo e a relação com o outro. Pode-se jogar com os dois, explorando limites, bordas e criando o hibridismo, mas na "ação sobre o outro" se privilegia a relação. No treinamento os atores são inicialmente dispostos em duas filas, frente a frente. A cada palma do instrutor, um a um se aproxima daquele que está à sua frente e realiza uma "ação sobre ele", invadindo o seu espaço corporal. Na segunda palma é o ator afetado que agora atua. Na terceira palma, os dois juntos improvisam, a fim de testar os limites da relação que surge a partir da "ação sobre o outro"- ou seja, deixam-se levar pelos estímulos, desenvolvendo as ações e desdobrando-as. Parte-se, então, para uma série de variações com o propósito de exacerbar - dilatar - os limites da relação com o outro.

Em algumas atuações de "Quem Tem Medo de Plínio Marcos?” foi a ação sobre o outro e, em outros, a tipificação que funcionou como alicerce da dilatação. A dilatação pode encontrar suporte na visualidade do tipo social, que oferece enquadramento às ações físicas e à presença do corpo, impedindo, ao mesmo tempo, que a atuação penda para uma resolução formal abstrata. Mas seria esta uma atuação realista? Não estaria mais perto da poética brechtiana, com o seu distanciamento crítico? Este é um dos limites: a borda que permite o naturalismo encostar na atuação épica quando se dilata, trazendo para a cena a visualidade do tipo social. Isto pode acontecer com Plínio Marcos, Tchekhov ou outros autores. Em leituras dramáticas realizadas na universidade, percebemos claramente o jogo de oscilação entre a cotidianidade e a tipificação quando um desenho bem definido - no que diz respeito à voz e a corpo - alude à visualidade de um tipo social característico, com uma série de ações e comportamentos a ele relacionados.

Em sua relação de oposição com a contenção e a cotidianidade, a tipificação tem gradações. O ator Leonardo Dariva, por exemplo, conseguiu, em "Barrela", uma dilatação dentre as atuações mais realistas: ambígua e contida. A relação com o outro entrou em jogo, neste caso, articulada a certa ideia de "depois": uma espécie de suspensão no tempo; um hiato recheado por tensões que geram o suspense. O enquadramento da relação com o outro, a expectativa da próxima ação, ou seja, o enquadramento dramático, comprime e filtra a tipificação; há acordo entre ambos. Já em "Querô", com os atores Marco Antonio Reis (Tainha) e Fagner Soares (Querô), não foi trabalhada esta suspensão do tempo. Ainda assim, no entanto, imprime-se a expectativa do depois, produzida, por sua vez, através da presença de uma arma (junto à reviravolta quando Querô a rouba e ameaça Tainha). Aqui percebemos que a diegese oferece enquadramento. É como se o ator, ao servir a uma ficção bem delineada, dilatasse junto com ela.

O que impera em "Barrela" é uma modalidade diferente de suspense, da qual já falou Hitchcock: a expectativa lenta de que algo está por vir em contraponto à surpresa abrupta na outra modalidade (TRUFFAUT, 1967). No caso de "Querô", o roubo repentino da arma "pega de surpresa" o espectador. Em "Barrela", a iminência de uma explosão vai sendo construída e, aos poucos, antecipada. Nos dois exemplos, há um manejo do tempo ficcional. Não se trata do ator fazer os gestos lentos ou rápidos, mas do desenrolar das ações inscritas na diegese, que salta ou se estende. Se isto estiver construído, $\mathrm{o}$ ator pode se dedicar à cotidianidade - como foi o caso de Leonardo Dariva e Fagner Soares sem medo de uma desdilatação, por assim dizer. Com isso, o realismo, como efeito da atuação, estaria, também, relacionado àquele fragmento delimitado na diegese que se configura como dramático - com uma curva no tempo.

Enquanto estávamos montando "Quem Tem Medo de Plínio Marcos?”, Dariva estava

\footnotetext{
${ }^{3}$ Diretor e dramaturgo argentino.
} 
treinando "Campo de Visão" ${ }^{4}$ nos ensaios de "As Criadas", outra montagem do grupo de pesquisa. Este treinamento extra-cotidiano promoveu dilatação. No "Campo de Visão", o que se prioriza é uma intensa produção formal extra-cotidiana, com o máximo da dilatação. As formas criadas no treinamento estavam impressas na memória corporal do ator, gerando resíduos que, sem querer, foram atualizados na cena de "Barrela", de maneira sutil, pressionando as bordas do corpo imbuídas da cotidianidade (enquadramento realista). Como duas bordas, uma pressionando a outra, o tecido da memória corporal como a borda interna e a cotidianidade (de "Barrela") como borda externa. Em cena, aparece o desenho de um corpo impregnado de cotidianidade e imobilidade - Dariva jogava com as duas - e mais o resíduo do repertório extra-cotidiano (extravasamento), dilatando, borrando o externo.

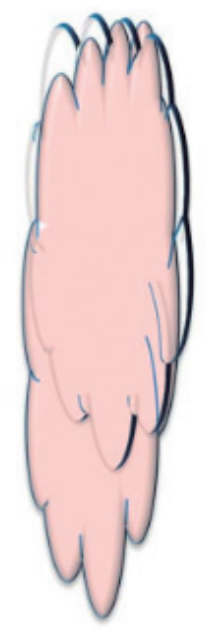

A extra-cotidianidade como resíduo e a cotidianidade como enquadre

São como dois territórios: o de dentro empurra o de fora, dilatando-o. O de dentro é o corpo atualizando o que está recentemente, ou a algum tempo, marcado - como praga, traço e peste involuntários; treina-se para marcar. Assim, o ator tem o que atualizar - que não seja a sua "desdilatação cotidiana" -, mesmo na atuação realista impregnada de cotidianidade. Constrói-se, assim, uma cotidianidade dilatada.
Este é um ponto chave: a demanda do treinamento extra-cotidiano para uma boa atuação realista no Teatro. Diante da necessidade da dilatação, é necessário treinar um repertório de formas estranhas, para que estas pressionem o corpo impregnado de cotidianidade, sendo que esta funciona como regra de jogo na atuação realista.

Mas, então, na ação sobre o outro, o que acontece com a borda extra-cotidiana adquirida com o treinamento do Campo de Visão? O Campo de Visão imprime vetores, abre caminhos para a ação sobre o outro; constitui, no corpo, uma plasticidade outra que permite a ação sobre o outro dilatar. O corpo fica mais elástico, mais aberto aos caminhos; ele é "rasgado", para viver estes caminhos "sujamente". Assim, quando a ação sobre o outro exigir um salto ou uma torção, o corpo possuirá este caminho, constituído durante o Campo de Visão e, durante a ação sobre o outro, diluído, sujo, manchado, abismado, subvertido, costurado. Vê-se a função do treinamento extra-cotidiano nos dois casos de dilatação: tanto na cotidianidade-imobilidade, quanto na ação sobre o outro. Acontece uma perspectiva de entrelaçamento, invasão mútua.

A partitura cênica de "Barrela" foi criada com regras de jogo - desviando-nos da representação do texto -, que organizam espaços: um ator sempre deitado enquanto os outros permanecem de pé; um ator sempre em um lado da cena, enquanto os outros permanecem no outro, trabalhando por oposição. As regras determinam uma organização espacial que, por sua vez, é diluída, à medida que começa a imperar a ação sobre o outro. As relações espaciais são absorvidas pela lógica dos enquadramentos internos e pela força das substituições (HAGEN, 2007). Paralelamente à montagem - com o improviso com regras de jogo e o texto memorizado pela escrita ${ }^{5}$-, os atores escreveram monólogos interiores e trabalharam fantasias e substituições, dilatando o enquadramento interno, para "sujarem" as bordas externas or-

\footnotetext{
${ }^{4}$ Procedimento sistematizado por Marcelo Lazzaratto na UNICAMP, constituído a partir do jogo Siga o Mestre. Os atores mimetizam os movimentos de quem está no seu campo de visão.

${ }^{5}$ O procedimento Memorização Através da Escrita (KHAN, 2009) é utilizado a partir de alguns desdobramentos propostos em pesquisa.
} 
ganizadas pelas regras de jogo. Os materiais internos, produzindo resíduos, também auxiliam a dilatação na ação sobre o outro. As regras de jogo se mantêm no empilhamento e ficam marcadas na partitura da cena (a sua estrutura espacial, apesar de residuais), à medida que outros materiais entram no arranjo. A ação sobre o outro se comporta como um vetor oposto à regra da organização espacial. Estes dois materiais alternam, disputam, entram em acordo. Às vezes, $o$ ator ocupado com a ação sobre o outro, se esquece da organização espacial; depois, lembra e retorna à regra. Isto dá movimento para a atuação, organicidade e vida, pois uma sucessão de trocas é inscrita como cadeia de impulsos.

Neste sentido, o treinamento da ação sobre o outro também ajudou na atuação realista. Seus resíduos não entraram em cena propositadamente, mas a invadiram, sem a intencionalidade dos atores estimulados pelos materiais ficcionais e os enquadramentos internos. Diante da necessidade de improvisar, o ator treinado na ação sobre o outro responde mais rápido, borrando as marcações criadas pelas regras de jogo. A ação sobre o outro deforma a harmonia do jogo espacial, ela produz o informe e o caótico. E considerando esta relação de borda entre forma e informe como um "desafio aos limites da forma" (DUNKER, 2006) - e a inscrição do informe como uma figuração do objeto a - a ação sobre o outro produz poética cênica.

Tendendo a romper as formas, romper as regras que estruturam espaço e tempo, a ação sobre o outro funciona como um elemento desestruturador, atrapalhador, perturbador. Os atores trabalham com um excesso (passam dos limites), que também se modaliza como figuração do "a"6. A relação espaço-temporal organizada tende a se romper através do caos que a ação sobre o outro imprime. A ação sobre o outro tende a extrapolar os limites organizacionais; é ruptura, é desestabilizadora. Não é a relação com o outro que impera, mas a destruição desta relação. Ao mesmo tempo, existe um reconhecer-se como personagem e os atores dizem "Vem do outro!"; "Não fui eu" (estimu- lados pela ideia de encarnação de uma alteridade quando o deixar-se levar pelas atualizações impera). Eles tendem a se enxergar como "personagem" quando a força advém da cena (e do jogo) - e o excesso de afeto não é voluntário. Associam esta irrupção, que os dessitua, como advinda "de outro" (personagem). Então, aparecem proposições como: "o personagem me levou", "vivi o personagem", "fui tomado pelo personagem". Eles dizem: "Não sei o que me deu", "não era eu”. Estas proposições testemunham a não intencionalidade da irrupção de um excesso de afeto. O outro é alvo da força de uma ação desmedida; é alvo de um excesso. É então que o efeito de realidade ocorre, aliado à dilatação e ao caos. Não se trata da dilatação limpa e bem desenhada, como na estética de Barba, trata-se de uma "dilatação-descarrego", que está mais para Artaud. $\mathrm{O}$ ator precisa estar aberto para vivenciá-la como experiência, no sentido de um atravessamento. É como o "voo no escuro", de que fala Anne Bogart (2011), e é preciso coragem para lançar-se.

\section{Considerações Finais}

Em parte, o efeito de realidade na atuação está veiculado à relação com o outro como enquadramento que situa a produção atoral e a justifica. A noção de "organicidade" está veiculada à produção de materiais ocultos suportando a dilatação da tessitura corporal e atingindo uma "zona de vulnerabilidade" ao acionar uma grafia de afeto que, por sua vez, é enquadrada pela relação com o outro. A "organicidade" tem a ver com a propriedade do ator se autoprovocar, produzindo enquadramentos internos e substituições (Hagen, 2007), deixando-se levar por atualizações de registros impregnados no corpo. Assim, pode-se estar "formal" e "orgânico" ao mesmo tempo, denunciando a condição de obreiro e desmanchando o efeito da realidade mimética (mesmo no realismo). Há um manejo das relações formais à medida que se joga com instruções de jogo, produção interna e atualizações (de registros e afetos). Organicidade, verdade, espontaneidade, naturalidade, são

\footnotetext{
${ }^{6}$ Uma das modalidades de figuração do objeto é o excesso. As outras são: o vazio, o informe, a anamorfose, os desafios aos limites da forma, a desjubjetivação.
} 
termos que precisam ser problematizados, pois carregam uma espécie de visão turva. Fala-se de "verdade" contrapondo-a ao exercício formal, que estaria na ordem do "falso". Mas "a verdade" consegue-se com um artifício. O par de opostos "verdade e mentira" não é operacional (e a noção de verdade muitas vezes vem com este brinde).

Colocamos o efeito de realidade na ordem da construção do enquadramento pela relação com o outro - mesmo que este outro seja "si próprio" quando se está sozinho em cena; organicidade como um acordar da grafia dos afetos; espontaneidade como da ordem da resolução de problemas em jogo a partir da divisão de foco e do manejo de um arranjo que implica esta resolução (que, por surgir em cena, aparece como espontânea); a naturalidade como algo técnico, que se produz com a divisão de foco e a impressão da cotidianidade; a vida como pulsão que borra os enquadramentos, os pressiona, por implicar a sua destruição - ou seja, a vida bagunça o jogo de enquadramentos, a pulsão é maior do que os pactos anteriormente nomeados, a vida como subversão da partitura.

Todas estas instâncias, que estão na ordem do que seria nomeado como um ideal da atuação "viva, orgânica, verdadeira", dependem de um dispositivo de jogo imposto e artificial. A "verdade", nesta revisão de termos, estaria relacionada com a produção do efeito estético. Pode-se ser "frio"; pode-se estar, inclusive, sem tônus ou densidade, e ter "verdade". Pode-se até não estar enlaçado pulsionalmente. Se o jogo de enquadramentos apontar para um "a", conforme a modalidade que se constrói e suas particularidades, se tem verdade. A "verdade" da poética estaria implicada neste "a” para o qual, com ela, se aponta.

A diegese está neste jogo. Sabe-se que é um elemento de estímulo: a personagem. Não paro de me surpreender com o encanto dos atores por esta instância. Chega-se à ideia de se transformar ("nele"), ser levado ("por ele"), se sentir ("ele"): uma fantasia pulsante, que também traz vida. Este campo imaginário constitui-se como um possível sentido para o estar em cena: "ser outro" (a operação de incorporação de uma alteridade que, de certa forma, o liberta "de si mesmo"). Trabalhar esta instância pode ser produtivo se, no entanto, a regra de jogo, que circunscreve o arranjo, não ficar esquecida. É preciso brincar com o diegético, refazê-lo, recompô-lo, destruí-lo, reconstruí-lo e enxergá-lo novamente, conforme as demandas de uma poética. Existe um jogo entre poética e diegese. Conforme a necessidade, refaz-se o diegético, que, inclusive, pode ser inscrito aos pedaços (pode-se imaginar qualquer coisa em um fragmento de cena que, no cinema, inclusive, se filma fora de ordem).

Os materiais internos em substituição (HAGEN, 2007) inscrevem poderosos efeitos. Eles "trazem" e "puxam" a libido do corpo (como se diz no Teatro, "o orgânico"). Trata-se de enlaçamento libidinoso, pulsional, a ponto de o ator dizer: "Não era eu"; "Não consegui parar". Aqui, ao contrário da diegese (personagem) são os materiais da própria referência de vida do ator que, escondidos, impulsionam a extrapolar os limites da intencionalidade e sentir-se como outro - por estar lidando com algo no limite do fora do controle. Trata-se de pensar quais elementos internos se quer utilizar: se os produzidos com a fantasia da encarnação da personagem ou com a vivência em nome próprio utilizada em segredo e travestida de ação diegética. Vislumbra-se como horizonte, o hibridismo. 


\section{REFERÊNCIAS}

ABRAHÃO SOUSA, L. M. O real e a poesia: nos entremeios litorâneos de Pêcheux e Lacan. Fragmentum (on-line), v. 47, pp. 155-167, 2017.

BARBA, E. A Canoa de Papel: Tratado de Antropologia Teatral. São Paulo: Hucitec, 1994.

BARBA, Eugenio \& SAVARESE, Nicola. A Arte Secreta do Ator. São Paulo: Hucitec, 1995.

BOGART, A. A Preparação do Diretor. São Paulo: Ed. Martins Fontes, 2011.

BURNIER, Luiz Otávio. A Arte do Ator - Da Técnica à Representação. Campinas:Ed. Unicamp, 2001.

DUNKER, Christian. A Imagem entre o Olho e o Olhar. In: Sobre Arte e Psicanálise. São Paulo: Escuta, 2006, v.1, pp. 14-29.

HAGEN, U. Técnica para o Ator: A Arte da Interpretação Ética. São Paulo: Ed. Martins Fontes, 2007.

KHAN, F. Reflexões sobre a prática da memória no ofício do ator de teatro. Revista Sala Preta, ECA/USP, v. 9, 2009.

KUSNET, E. Ator e Método. São Paulo: Ed. Hucitec, 2003.

LAZZARATTO, M. Campo de Visão e Linguagem Cênica. São Paulo: Ed. Associação de Arte, 2011.

MARCONDES, D. A Filosofia da Linguagem de J. L. Austin. In: AUSTIN, J. L. Quando Dizer é Fazer: Palavras e Ação. Porto Alegre: Ed. Artes Médicas, 1990.

ROUBINE, J. Introdução às Grandes Teorias do Teatro. Rio de Janeiro: Zahar, 2003.

SPOLIN, V. Improvisação para o Teatro. São Paulo: Ed. Perspectiva, 2015.

TRUFFAUT, F. Hitchcock-Truffaut: entrevistas. São Paulo: Brasiliense, 1967. 